\title{
Tissue Cytokine Adenoid Experssion in Hypertrophic Adenoid Gland in Children with Allergic Rhinitis
}

\author{
Fengjuan Zhu ${ }^{1,2}$, Kaiyue Sun ${ }^{1}$, Liang Yư ${ }^{1}$, Shujuan Sun ${ }^{1}$, Yuzhu Wan ${ }^{1}$ and Li Shi ${ }^{1}$ \\ ${ }^{1}$ Department of Otolaryngology - Head and Neck Surgery, Shandong Provincial ENT Hospital, Cheeloo College of Medicine, Shandong \\ University, Jinan, Shandong, P.R. China \\ ${ }^{2}$ Department of Otolaryngology-Head and Neck Surgery, The People's Hospital of Rizhao,126 Taian Road,Rizhao, Shandong, P.R.China
}

\begin{abstract}
Objective: To investigate the inflammatory pattern in terms of inflammatory cells and cytokines expression in children with adenoid hypertrophy $(\mathrm{AH})$ and coexistent allergic rhinitis (AR).

Study Design: A cross-sectional analytical study.

Place and Duration of Study: Department of Otolaryngology-Head and Neck Surgery, Shandong Provincial ENT Hospital, Cheeloo College of Medicine, Shandong University, Jinan, Shandong P. R. China, from October 2018 to August 2020.

Methodology: A sample of 102 children with $\mathrm{AH}$, who underwent adenoidectomy were enrolled. They were divided into two groups of $A H$, alone and $A H$ with $A R(A H+A R)$. A routine complete blood count, and the number of eosinophils in adenoid tissue was measured using hematoxylin-eosin staining. The tissue expression of cytokines was carried out using real-time quantitative PCR.

Results: Forty-eight children (47\%) were diagnosed with AR. The number and percentage of eosinophils in peripheral blood and adenoid tissue were statistically $(p<0.05)$ higher in the group of $A H+A R$ than $A H$ alone. Furthermore, in patients with $A H+A R$, the mRNA expression levels of IL-12 and IFN- $\gamma$ decreased, while IL-4, IL-8, IL-18, IL-33, H2R, LTR1, LTR2 and GCR all increased in adenoid tissue.

Conclusion: The pathological mechanism underlying adenoid hypertrophy in children with comorbid allergic rhinitis can be involved with predominant tissue eosinophilia and type 2 (or Th 2 ) inflammation.
\end{abstract}

Key Words: Adenoid hypertrophy, Allergic rhinitis, Inflammatory features, Cytokines, Eosinophils.

How to cite this article: Zhu F, Sun K, Yu L, Sun S, Wan Y, Shi L. Tissue Cytokine Adenoid Experssion in Hypertrophic Adenoid Gland in Children with Allergic Rhinitis. J Coll Physicians Surg Pak 2021; 31(08):903-909.

\section{INTRODUCTION}

Adenoid hypertrophy $(\mathrm{AH})$ is a common disease in children and is associated with nasal obstruction, sleep-disordered breathing, and secretory otitis media in children. It could lead to daytime sleepiness, inattention, which also affect the development of the maxillofacial region, teeth, and intelligence. ${ }^{1}$ The adenoids, which mainly constituted by B-cell lymphocytes and $T$ cells, are a conglomerate of peripheral lymphatic tissue. Because of prolonged antigenic stimulation associated with chronic inflammation, adenoids enlarged pathologically. The most relevant inflammatory conditions are respiratory infections and allergy forchildren with nasal obstruction.

Correspondence to: Li Shi, Department of Otolaryngology

- Head and Neck Surgery, Shandong Provincial ENT

Hospital, Cheeloo College of Medicine, Shandong Univer-

sity, Jinan, Shandong, P.R. China

E-mail: shili126@sina.com

Received: April 17, 2021; Revised: June 07, 2021;

Accepted: June 30, 2021

DOI: https://doi.org/10.29271/jcpsp.2021.08.903
The nasal and sinus mucosa and adenoids are the most closely situated cluster of organised lymphatic tissue that inflammatory status within them could influence each other, so the recurring upper airway infections and allergic rhinitis may stimulate adenoids and lymphoid tissue hyperplasia.

In clinical management, the current preferred treatment for $\mathrm{AH}$ is surgical resection. AH children are often comorbid with allergic rhinitis (AR). ${ }^{2}$ Some literature reports suggested that AR may trigger $A H{ }^{3}$ The severity of $A R$ would get worse and disease duration was prolonged, if AR patients companied with $\mathrm{AH}^{4}{ }^{4}$ However, from other clinical reports, AH and AR were significantly negatively correlated. ${ }^{5,6}$ Therefore, the causal relationship between these two commonly comorbid diseases remains unclear. A better understanding of the pathological relationship between $A H$ and AR will help in improving clinical management of these two common diseases in children.

The aim of this study was to investigate the inflammatory pattern of $\mathrm{AH}$ in paediatric patients with and without AR.

\section{METHODOLOGY}

Accumulative adenoid tissues were obtained from the patients, who underwent adenoidectomy in the Department of Otolaryn- 
gology in Shandong ENT Provincial Hospital, from October 2018 to August 2020. They were divided into two groups of $A H$ without $A R(A H, n=54)$ and $A H$ with $A R(A H+A R, n=48)$. The inclusion and exclusion criteria include all study patients were not accompanied by acute adenoiditis or other acute respiratory infection and were not treated by both systemic or topical glucocorticoids or antibodies for three months before the study. Adenoid tissues were divided into two parts, one was fixed in formalin for histological evaluation of infiltration of inflammatory cells (e.g., eosinophils), and the other part was immersed in RNAlater for extracting RNA to detect corresponding gene expressions. The cell counts from a routine complete blood count were recorded. Approval for this study was obtained from the Institutional Review Board of Shandong Provincial ENT Hospital, Cheeloo College of Medicine, Shandong University, Jinan, Shandong P.R. China.

The diagnostic criteria for AR was based strictly on the recommendation by the ARIA document. ${ }^{7}$ In addition, a positive serum specific lgE ( $\geq 0.35 \mathrm{kU} / \mathrm{l} \mathrm{CAP} \mathrm{Pharmacia,} \mathrm{Uppsala,} \mathrm{Sweden)} \mathrm{to} \mathrm{at}$ least one or more common local allergens was confirmed.

The size of adenoid was divided into four degrees according to the degree of the posterior nostril after the adenoid is blocked by the electronic nasopharyngoscopy: ${ }^{8}$ I: posterior nostril $\leq$ $25 \%$ after adenoid blockage; II: $26-50 \%$ posterior nostril after adenoid blockage; III: 51-75\% posterior nostril after adenoid blockage; and IV: posterior nostril after adenoid blockage $>75 \%$. Children with degree III or IV were included in this $\mathrm{AH}$ study.

As HA can compress or block the eustachian tube and cause secretory otitis media, the diagnosis for secretory otitis media for all patients were included. It is based on the combination of conductive hearing loss in a pure-tone hearing test; tympanic indentation is obvious or shows liquid level or air bubbles; and acoustic impedance test shows B-type or C-type curve. A clear diagnosis can be made for children 5-year or older through the above three tests. For children under 5 years, the diagnosis could be confirmed by otoscopy and acoustic impedanceexamination.

Fresh tissue biopsies were immediately embedded in paraffin. The 4- $\mu \mathrm{m}$ serial sections were obtained from each paraffin blocked tissue. Eosinophil infiltration was evaluated based on $H \& E$ staining, and 5 random sections for all samples were selected to record the numbers of the eosinophils under high-power fields (HPF, 400x magnification) in a blind fashion. All samples were assessed in a blinded fashion by two independent researchers. ${ }^{9}$

The total RNA of samples in RNAlater was extracted by trizol (Invitrogen, Life Technologies,USA). The cDNA was synthesised with reversing transcription kit (Thermo, USA) and the qRT-PCR was performed with Mastercycler Nexus (Eppendorf, Germany). The primers' information is described in detail in Table I. Relative gene expression was calculated using the comparative $2^{-\mathrm{ct}}$ method with the housekeeping gene GAPDH as a reference. The tested cytokines include: Th1-related cytokines mainly include IL-2, IL-8, IL-12, TNF- $\alpha$, and IFN- $\gamma$. Th2related cytokines mainly include IL-4, IL-5, IL-13, IL-18, IL-33, and IL-25. The related receptors include H1R, H2R, H3R, H4R, LTR1, LTR2 and GCR.

Table I: SYBR green gene expression assays.

\begin{tabular}{|c|c|}
\hline Primer & Assay \\
\hline IL2 & $\begin{array}{l}\text { F: 5'-ATCCCAAACTCACCAGGATGC } \\
\text { R: 5'-AGATGTTCAGTTCTGTGGCCT }\end{array}$ \\
\hline IL4 & $\begin{array}{l}\text { F: 5'-TTCCTGAAACGGCTCGACAG } \\
\text { R: 5'-CGTACTCTGGTTGGCTTCCT }\end{array}$ \\
\hline IL5 & $\begin{array}{l}\text { F: 5'-TCGAACTCTGCTGATAGCCA } \\
\text { R: 5'-CTCCAGTGTGCCTATTCCCT }\end{array}$ \\
\hline IL-8 & $\begin{array}{l}\text { F:5'CTCTGTGTGAAGGTGCAGTIT } \\
\text { R:5'-GTITCCTTGGGGTCCAGACA }\end{array}$ \\
\hline IL12 & $\begin{array}{l}\text { F: 5'-CCATCAACGCAGCACTTCAG } \\
\text { R: 5'-CACCCTGTTGATGGTCACGA }\end{array}$ \\
\hline IL13 & $\begin{array}{l}\text { F: 5'-AGGAGGGTTAGGGAGGGGTA } \\
\text { R: 5'-GGGCACCCACTGTAATGCTA }\end{array}$ \\
\hline IL18 & $\begin{array}{l}\text { F: 5'-TGACCAAGGAAATCGGCCTC } \\
\text { R: 5'-GGTCCGGGGTGCATTATCTCT }\end{array}$ \\
\hline IL25 & $\begin{array}{l}\text { F: 5'-CATGGGAACCCACACCTACA } \\
\text { R: 5'-GCTGTTGAGGGGTCCATCTT }\end{array}$ \\
\hline IL33 & $\begin{array}{l}\text { F: 5'-GTGAAAAACCACTGCCAGACC } \\
\text { R: 5'-CTCAACCCAAGACTCACAGGT }\end{array}$ \\
\hline IFN- $\gamma$ & $\begin{array}{l}\text { F: 5'-AAGTGATGGCTGAACTGTCG } \\
\text { R: 5'-TACTGGGATGCTCTTCGACC }\end{array}$ \\
\hline$T N F-\alpha$ & $\begin{array}{l}\text { F: 5'-GGGCAGGTCTACTTTGGGAT } \\
\text { R: 5'-AGGTTGAGGGTGTCTGAAGG }\end{array}$ \\
\hline$H 1 R$ & $\begin{array}{l}\text { F: 5'-GTGAGGGCAACAAGACCACT } \\
\text { R: 5'-GGTTGAGCCCTACTGTGACC }\end{array}$ \\
\hline$H 2 R$ & $\begin{array}{l}\text { F: 5'-CCACCATCAGGGAGCACAAA } \\
\text { R: 5'-GCGGTGAAGTAGGGAAACCA }\end{array}$ \\
\hline$H 3 R$ & $\begin{array}{l}\text { F: 5'-TCACCCGAGCGGTCTCATA } \\
R: 5^{\prime}-A G A A C T C G G C A T A G C A G T G G\end{array}$ \\
\hline$H 4 R$ & $\begin{array}{l}\text { F: 5'-CGGAATGGTACATCCTTGCC } \\
\text { R: 5'-GGATGGCTTTGGCACCTACT }\end{array}$ \\
\hline CYSLTR1 & $\begin{array}{l}\text { F: 5'-CTTTGGTGACTTCTTGTGCCG } \\
\text { R: 5'-CCTACACACACAAACCTGGCT }\end{array}$ \\
\hline CYSLTR2 & $\begin{array}{l}\text { F: 5'-CTGCGGGTTTCTCACAGGAA } \\
\text { R: 5'-TGCCAAGGCCAGTGTGATAA }\end{array}$ \\
\hline$G C R$ & $\begin{array}{l}\text { F: 5'-ACCCTGGTGTCACTGTTGGA } \\
\text { R: 5'-ATCACTTGCCGCCCTCCTAA }\end{array}$ \\
\hline GAPDH & $\begin{array}{l}\text { F: 5'-GCACCGTCAAGGCTGAGAAC } \\
R: 5^{\prime}-T G G T G A A G A C G C C A G T G G A\end{array}$ \\
\hline
\end{tabular}

Statistical analyses were conducted using GraphPad. Prism v 5.0. Data were shown as mean $\pm S D$, frequencies and percentages. Comparisons of parameters between two groups were analysed using unpaired Student's t-test. Gender ratio, age difference, the prevalence of secretory otitis media between two groups were compared with the Chi-square test. $p$-value $<0.05$ was considered as statistically significant.

\section{RESULTS}

The ages were $5.167 \pm 0.328$ years in $\mathrm{AH}$ alone group $(\mathrm{N}=54)$ and $5.417 \pm 0.406$ years in the AH+AR group $(N=48)$. There were 35 males (64.8\%) in the $\mathrm{AH}$-alone group and 40 males $(83.3 \%)$ in the $A H+A R$ group. There was no statistically significant difference in age $(p=0.630)$ between the two groups, but a trend towards more males in all patients $(p=0.034)$. The incidence of otitis media was 25 (46.3\%) in the $\mathrm{AH}$ alone group and $26(54.2 \%)$ in the AH+AR group ( $p=0.428)$. Forty-eight ( $47 \%$ ) of children were diagnosed with AR.

The number and percentage of eosinophils, neutrophils, and basophils; and their differences between the two groups were analysed and shown in Figure 1. There were significant differences in the number and proportion of peripheral blood eosinophils between the two groups $(p<0.0001)$. 


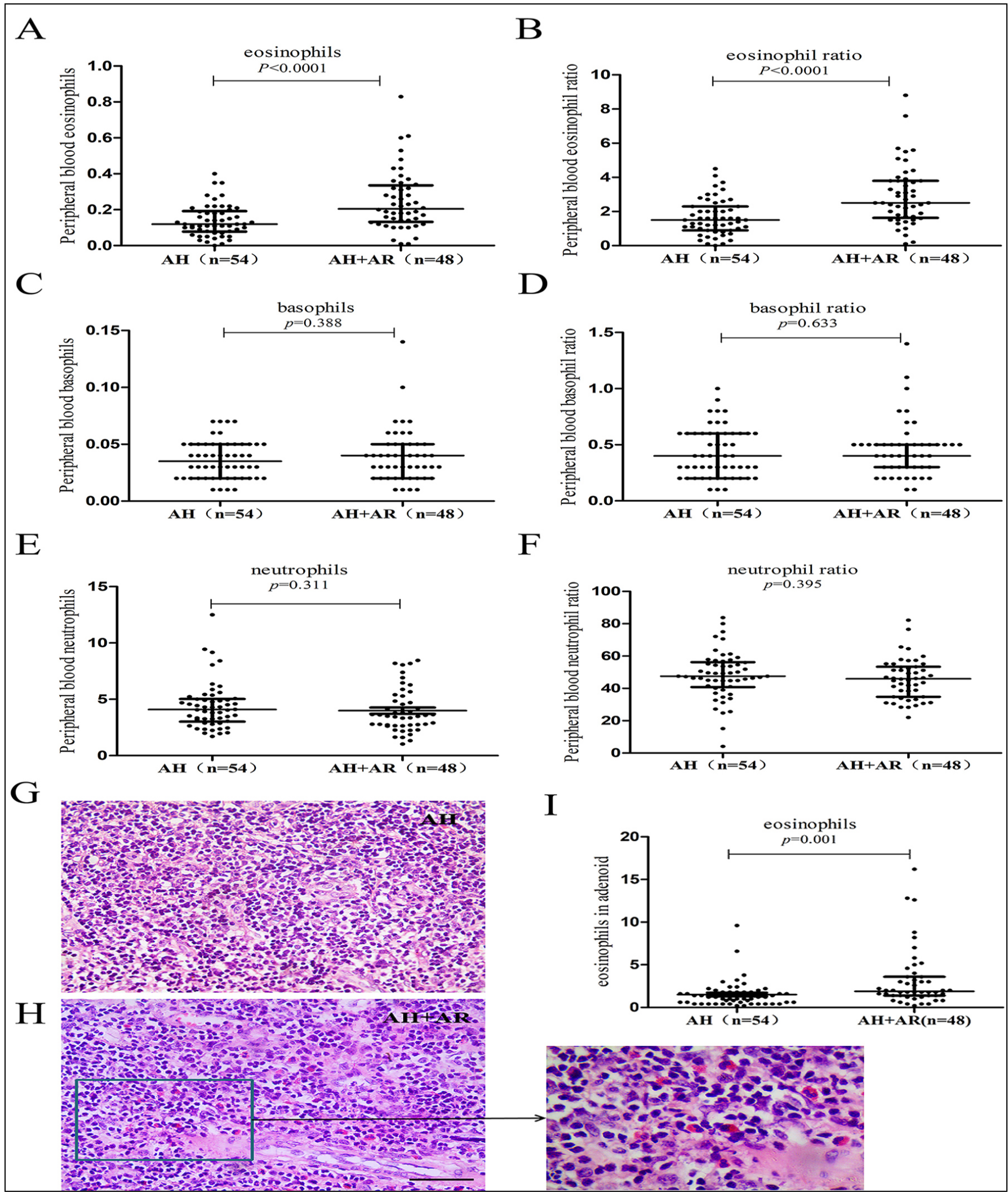

Figure 1: The differences in clinical features between AH and AH+AR patients. A, C and E are the numbers of eosinophils, basophils, and neutrophils in the peripheral blood of the two groups of children. B, D, and F are the proportions of eosinophils, basophils, and neutrophils in the peripheral blood of the two groups of children. G: HE images of adenoids in children with adenoid hypertrophy without allergic rhinitis under a 400x microscope. H: HE images of adenoid tissue in children with adenoid hypertrophy accompanied by allergic rhinitis under 400 times microscope. I: Comparison of eosinophil counts of adenoids in two groups of children under $400 \times$ microscope. 
A

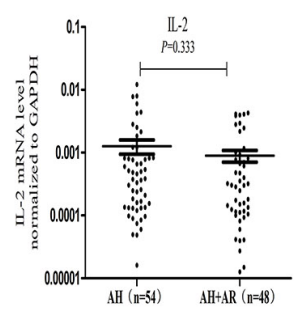

F

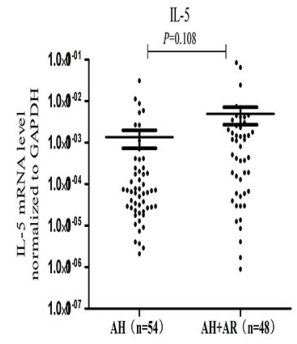

K

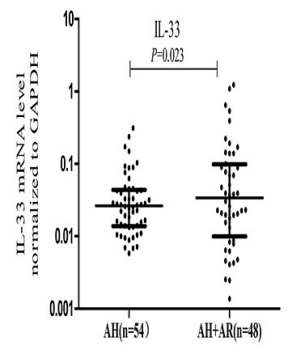

B

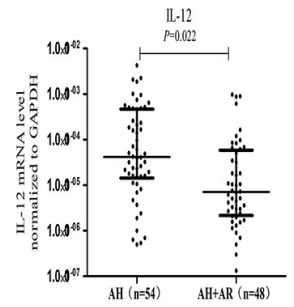

G

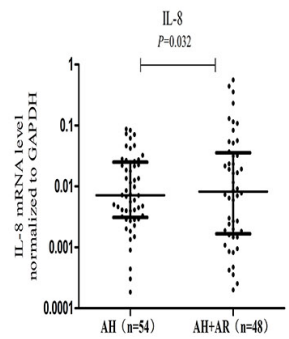

L

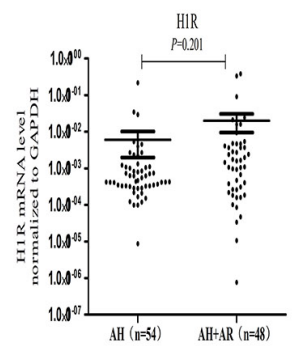

C

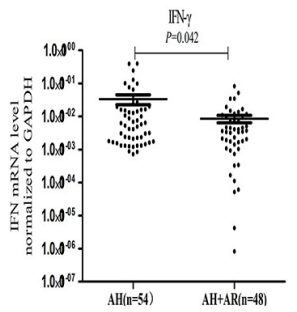

H

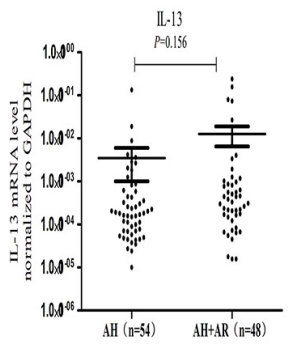

M

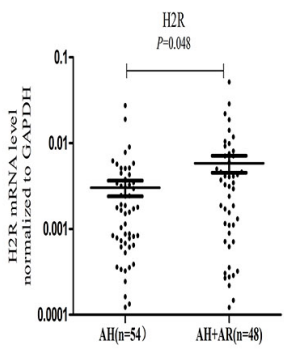

D

E
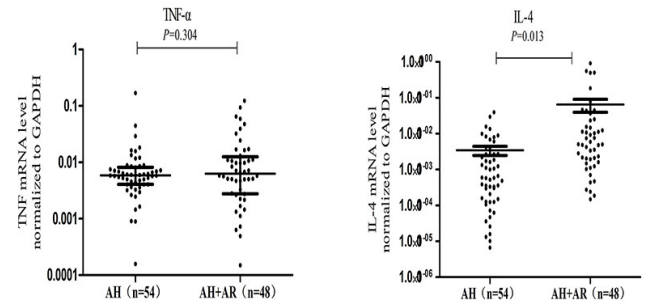

J
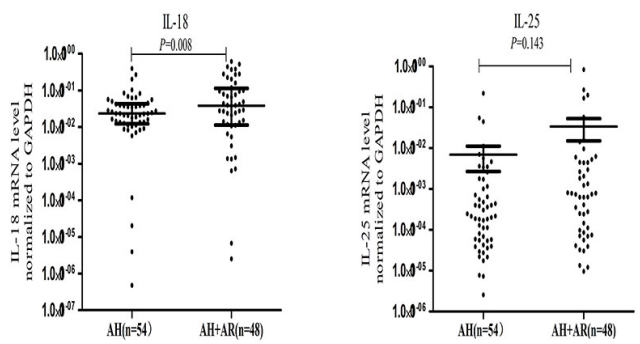

N

0

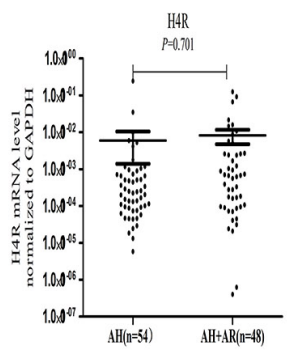

P

Q
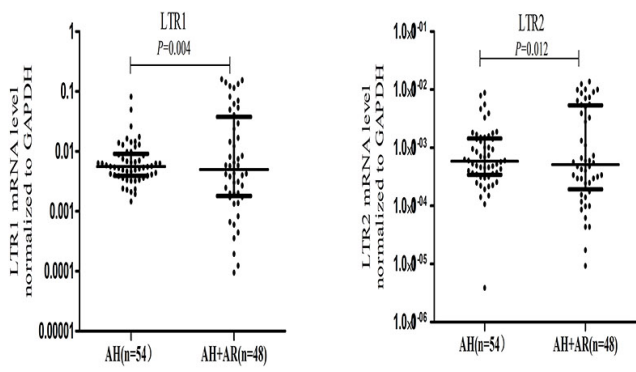

Figure 2: The relative expression of genes that related with AR inflammation in mRNA. A-D: Th1-related inflammatory factors. A,B,C and $D$ are IL-2,IL-12,IFN- $\gamma$, TNF- $\alpha$ mRNA level normalised to GAPDH in two groups of children. E-K: Th2-related inflammatory factors. E, F, G, H, I, J and K are IL-4, IL-5, IL-8, IL-13, IL-18, IL-25 and IL-33 mRNA level normalised to GAPDH in two groups of children. L-N: Histamine receptor, 0: Glucocorticoid receptor, P-Q: Leukotriene receptor. L, M and N are H1R, H2R are H4R mRNA level normalised to GAPDH in two groups of children. $O$ is GCR mRNA level normalised to GAPDH in two groups of children. P, Q are LTR1, LTR2 mRNA level normalised to GAPDH in two groups of children.

The count and proportion of eosinophils in the AH+AR group were highly increased. There was no difference in the number and proportion of peripheral blood neutrophil and basophil cells between the $\mathrm{AH}$ alone and $\mathrm{AH}+\mathrm{AR}$ groups $(p>0.05)$.
HE staining of adenoid tissue sections showed a significant difference between the two groups in eosinophil counts ( $p=0.001$, Figure 1$)$. Neutrophils and basophils were occasional or absence in the $\mathrm{AH}$ tissue. 
The expression levels of mRNA of Th- 1 and Th-2 related inflammatory cytokines and allergy-related receptors are shown in Figure 2.

\section{DISCUSSION}

$\mathrm{AH}$ is the most common underlying risk factor of obstructive sleep apnoea syndrome (OSAS) in children. It could cause Eustachian tube pharyngeal obstruction and then lead to non-purulent or suppurative otitis media, hearing loss, tinnitus, and ear blocks. AH is often comorbid with rhinitis and rhinosinusitis in children. Due to long-term mouth breathing, AH patients often suffered from the adenoid face, which affects the development of facial bones, resulting in the long and narrow maxilla, narrowed hard palate, protruded teeth, not aligned dentition, and upturned upper lip. Surgical removal of hypertrophic adenoids or tonsils is the first-line treatment for OSAS in children. ${ }^{10}$ However, the risk of bleeding after adenoid surgery is reported. ${ }^{11}$

Studies on the relationships between $\mathrm{AH}$ and $\mathrm{AR}$ are limited and the main focus was on the influence of $A R$ on sleep disordered breathing in children with $\mathrm{AH}^{12} \mathrm{~A}$ recent review suggested the possible relationships between AR and other pathogenic factors, such as AH. Eustachian tube dysfunction related to the adenoids may also have an allergy-related functional component. The pathological AH suffered from exaggerate antigenic stimulation and was mainly mediated by Th1 and/or Th2 mediated inflammatory responses. A study showed that adenoids were involved in IgE-mediated sensitisation with local differentiation of IgE-producing plasma cells. ${ }^{13}$ But the correlations among allergy, recurrent infections, and AH remain unclear. Colavita et al. found that $80 \%$ of children with AR and $\mathrm{AH}$ were not notably benefited from the adenoidectomy ${ }^{14}$ Anti-allergic therapy is important to eliminate local inflammation, which prevents adenoid regrowth and reduces nasal symptoms. Moreover, anti-allergic treatment can effectively alleviate the clinical symptoms and avoid adenoid surgery for the patients, but it lacks a theoretical basis.

Tissue eosinophilia is an intrinsic factor of allergy. Eosinophils are the major effector cells in allergic inflammation. Tissue eosinophilia was used to describe the allergic inflammation in the nasal and bronchial mucosa, also in adenoid and tonsil tissue. It is reported that the number of eosinophils was significantly higher in the adenoid tissue of atopic patients. ${ }^{15}$ Similarly, the present authors found the number of eosinophils in adenoid tissue and peripheral blood was significantly higher in AR children as compared to nonAR ones. Besides, the neutrophils had a higher tendency in the $\mathrm{AH}$ group than in the $\mathrm{AH}+\mathrm{AR}$ group. This indicates that the inflammatory status may lead to $\mathrm{AH}$ and the mechanism underlying $\mathrm{AH}$ and $\mathrm{AH}+\mathrm{AR}$ may be different. $\mathrm{AR}$ is also often associated with adeno-tonsillar disease, positive correlation has been shown in many studies between AR and adeno-tonsillar diseases. ${ }^{16,17}$
The expression of T-bet is mainly restricted to the Th1 cell type, while IFN- $\gamma$ can be produced by several cell types including CD4+ Th1 cells, CD8+ cells, natural killer cells, and B cells. ${ }^{18}$ From the present data, Th1-related inflammatory factors were significantly higher in the $\mathrm{AH}$ group than Th2related inflammatory factors, while Th2-related inflammatory factors were higher in $\mathrm{AH}+\mathrm{AR}$ group than the $\mathrm{AH}$ group. IL-12 and IFN- $\gamma$ in the AH alone group increased, while IL-4, IL-8, IL-18, and IL-33 in the AH+AR group were all up-regulated obviously. These data indicated that IL-12 and IFN-Y may contribute to the development of chronic infectious inflammation in patients. IL-4, IL-8, IL-18, and IL-33 may contribute to the development of allergic reactions in patients. It is suggested that allergies and infections may be the two main causes of $\mathrm{AH}$, and pharmacotherapy should be indicated as the first-line treatment.

Previous studies demonstrated that the medical use of intranasal corticosteroids like fluticasone propionate, or mometasone furoate for the treatment of $\mathrm{AH}$ could significantly improve the life quality of the patients. ${ }^{19,20}$ Thus, it may be due to the anti-inflammatory effect. The anti-inflammatory effect of steroids helps to reduce adenoidal and nasopharyngeal inflammatory status or reduce the possibility of adenoid development as an infection reservoir. One study proved that adenoid tissue includes many glucocorticoid receptors; and messenger RNA strengthens these probable mechanisms. ${ }^{21}$ Cysteinyl leukotriene receptor (CYSLTR) plays essential roles in mediating a variety of allergic reactions and hypersensitivity. ${ }^{22}$ It has been reported that the expression level of CYSLTR was upregulated in the hypertrophic adenoid, which indicated CYSLTR is an essential factor in the progression of this disease. Cysteinyl leukotriene receptors play important roles in mediating airway remodeling. The expression level of CYSLTR was increased in adenoid tissues of children with $\mathrm{AH}$ compared with the healthy children. ${ }^{23}$ However, the involvement of CYSLTR in AH still has not been well studied, except one recent study reported that montelukast sodium seems to be effective in the reduction of the size of adenoids and improvement in clinical manifestations. ${ }^{24}$ There are still few studies on histamine receptors in adenoids. In this study, the related receptor expression level of H2R, LTR1, LTR2, and GCR were all increased significantly in the AH+AR group. There were no statistical differences between the two groups with regard to $\mathrm{H} 1 \mathrm{R}$ and H4R. H3R expression is too low to be undetectable in many samples. These results indicated that glucocorticoid and anti-leukotriene treatment should be effective, while Anti-H1 treatment may not be the first choice for AH+AR patients.

\section{CONCLUSION}

The incidence of $A R$ in children with $A H$ is higher than the average prevalence of AR in children; and IgE-mediated type 2 inflammation with eosinophilia could be an important pathogenic factor associated in $\mathrm{AH}$. This study suggests that anti-inflammatory treatment can be a first-line treatment prior to adenoidectomy in children with $\mathrm{AH}$ and $\mathrm{AR}$. 


\section{ACKNOWLEDGMENT:}

This study was supported by the grant National Science Foundation of China (81670909, 81873692), Key R \& D Program of Shandong Province (2018CXGC1214).

\section{ETHICAL APPROVAL:}

Approval for this study was obtained from the Institutional Review Board of The Second Hospital of Shandong University, Cheeloo College of Medicine, Shandong University [KYLL-2018(KJ) P-0025].

\section{PATIENTS' CONSENT:}

All parents of the patients signed a document of informed consent.

\section{CONFLICT OF INTEREST:}

The authors declared no conflict of interest.

\section{AUTHORS' CONTRIBUTION:}

FZ: Experimental operation, supervision, resource, analysis and interpretation, drafting the work, literature search.

KS: Experimental operation, analysis and interpretation, revising, literature search.

LY: Analysis and interpretation, materials, data collection.

SS: Analysis and interpretation, materials, data collection.

YW: Analysis and interpretation, materials, data collection.

LS: Conception and design, critical reviews, approval of the final version.

\section{REFERENCES}

1. Wang DY, Bernheim N, Kaufman L, Clement P. Assessment of adenoid size in children by fibreoptic examination. Clin Otolaryngol Allied Sci 1997; 22(2):172-7. doi: 10.1046/ j.1365-2273.1997.00002.x.

2. Nuhoglu C, Nuhoglu Y, Bankaoglu M, Ceran O. A retrospective analysis of adenoidal size in children with allergic rhinitis and nonallergic idiopathic rhinitis. Asian Pac J Allergy Immunol 2010; 28(2-3):136-40.

3. Adegbiji WA, Olajide GT, Olajuyin AO, Aremu SK, Olusola AG. Pattern of allergic rhinitis among children in Ekiti, Nigeria. Int J Pediatr Otorhinolaryngol 2018; 106:75-9. doi:10. 1016/j.ijporl.2018.01.014.

4. Dogru M, Evcimik MF, Calim OF. Does adenoid hypertrophy affect disease severity in children with allergic rhinitis? Eur Arch Otorhinolaryngol 2017; 274(1):209-13. doi:10.1007/ s00405-016-4196-x.

5. Eren E, Arslanoğlu S, Erdem SB, Nacaroğlu T, Karkıner CŞ, Can $D$, et al. Chicken or the egg: The dilemma of allergic rhinitis versus adenoid hypertrophy. Rhinol 2015; 53(2): 154-9. doi:10.4193/Rhin14.013.PMID:26030038.

6. Ameli F, Brocchetti F, Tosca MA, Signori A, Ciprandi G. Adenoidal hypertrophy and allergic rhinitis: Is there an inverse relationship? Am J Rhinol Allergy 2013; 27(1):e5-10. doi:10.2500/ajra.2013.27.3854.

7. Bousquet J, Khaltaev N, Cruz AA, Denburg J, Fokkens WJ, Togias A, et al. Allergic Rhinitis and its Impact on Asthma (ARIA) 2008 update (in collaboration with the World Health Organization, GA (2) LEN and AllerGen). Allergy 2008; 63
Suppl 86:8-160. doi: 10.1111/j.1398-9995.2007.01620.x.

8. Sun H, Zhang L. Otorhinolaryngology, Head and Neck Surgery. ed.9th,People's Medical Publishing House 2018.

9. Payne SC, Early SB, Huyett P, Han JK, Borish L, Steinke JW. Evidence for distinct histologic profile of nasal polyps with and without eosinophilia. Laryngoscope. 2011; 121(10): 2262-7. doi:10.1002/lary.21969.

10. Choi JH, Oh JI, Kim TM, Yoon HC, Park IH, Kim TH, et al. Long-term subjective and objective outcomes of adenotonsillectomy in Korean children with obstructive sleep apnea syndrome. Clin Exp Otorhinolaryngol 2015; 8(3):256-60. doi:10.3342/ceo.2015.8.3.256.

11. Urík M, Bartoš M, Šikolová S, Jančíková J, Perceová K, Jarkovský J, et al. Risk factors for postoperative bleeding after adenoidectomy. Children (Basel) 2021; 8(3):242. doi:10.3390/children8030242.

12. Liu J, Wu Y, Wu P, Xu Z, Ni X. Analysis of the impact of allergic rhinitis on the children with sleep disordered breathing. Int J Pediatr Otorhinolaryngol 2020; 138:110380. doi:10.1016/j.ijporl.2020.110380.

13. Papatziamos G, Van Hage-Hamsten M, Lundahl J, Hemlin C. IgE-positive plasma cells are present in adenoids of atopic children. Acta Otolaryngol 2006; 126(2):180-5. doi:10. 1080/00016480500265976.

14. Colavita L, Miraglia Del, Giudice M, Stroscio G, Visalli C, Alterio $T$, et al. Allergic rhinitis and adenoid hypertrophy in children: Is adenoidectomy always really useful? J Biol Regul Homeost Agents 2015; 29(2 Suppl 1):58-63.PMID: 26634589.

15. Ekici NY, Görgülü O, Yucel G, Külahcı Ö, Arıkan OK, Durmaz C. Can the number of eosinophils in adenoid and tonsil tissue determine the allergy in children? Int J Pediatr Otorhinolaryngol 2018; 108:35-39. doi:10.1016/j.ijporl.2018. 02.008 .

16. Evcimik MF, Dogru M, Cirik AA, Nepesov MI. Adenoid hypertrophy in children with allergic disease and influential factors. Int J Pediatr Otorhinolaryngol 2015; 79(5):694-7. doi: 10.1016/j.ijporl.2015.02.017.

17. Atan Sahin O, Kececioglu N, Serdar M, Ozpinar A. The association of residential mold exposure and adenotonsillar hypertrophy in children living in damp environments. Int J Pediatr Otorhinolaryngol 2016; 88:233-8. doi:10.1016/j.ijporI.2016.07.018.

18. Szabo SJ, Kim ST, Costa GL, Zhang X, Fathman CG, Glimcher LH. Pillars article: A novel transcription factor, T-bet, directs Th1 lineage commitment. Cell 2000; 100:655-9. J Immunol 2015; 194(7):2961-75. PMID: 25795787.

19. Demirhan H, Aksoy F, Ozturan O, Yildirim YS, Veyseller B. Medical treatment of adenoid hypertrophy with "fluticasone propionate nasal drops". Int J Pediatr Otorhinolaryngol 2010; 74(7):773-6.doi: 10.1016/j.ijporl.2010.03.051.

20. Ahmed MR, Abou-Halawa AS, Ibrahim IH, Zittoon RF, Makary EFY. Effect of topical mometasone furoate on adenoidal lymphoid tissue: A light microscopic study. J Laryngol Otol 2019; 133(2):106-9. doi:10.1017/S0022215118002268.

21. Zhou Z, Ni H, Li Y, Jiang B. LncRNA XIST promotes inflammation by downregulating $\mathrm{GR} \alpha$ expression in the adenoids of children with OSAHS. Exp Ther Med 2021; 21(5):500.- 
doi:10.3892/etm.2021.9931.

22. Gusach A, Luginina A, Marin E, Brouillette RL, Besserer-Offroy É, Longpré JM, et al. Structural basis of ligand selectivity and disease mutations in cysteinyl leukotriene receptors. Nat Commun 2019; 10(1):5573. doi:10.1038/ s41467-019-13348-2.
23. Gao W, Li J, Li Q, An S. CYSLTR1 promotes adenoid hypertrophy by activating ERK1/2. Exp Ther Med 2018; 16(2):966-70.doi:10.3892/etm.2018.6282.

24. Naqi SA, Ashfaq AH, Umar MA, Karmani JK, Arshad N. Clinical outcome of Montelukast Sodium in Children with Adenoid Hypertrophy. Pak J Med Sci 2021; 37(2):362-6. doi:10.12669/pjms.37.2.2670. 